\title{
Risk factors for anterior bone loss in cervical disc arthroplasty
}

\author{
David Christopher Kieser, MBChB, PhD, FRACS,1 \\ Derek Thomas Cawley, MMedSc MCh, FRCS Orth, ${ }^{2}$ Takashi Fujishiro, MD, ${ }^{2}$ Simon Mazas, MD, ${ }^{2}$ \\ Louis Boissière, MD, ${ }^{2}$ Ibrahim Obeid, MD, MS, ${ }^{2}$ Vincent Pointillart, MD, PhD, ${ }^{2}$ \\ Jean-Marc Vital, MD, PhD, ${ }^{2}$ and Olivier Gille, MD, $\mathrm{PhD}^{2}$
}

1Department of Orthopedic Surgery and Musculoskeletal Medicine, University of Otago, Christchurch School of Medicine, Christchurch, Canterbury, New Zealand; and 'L'Institut de la Colonne Vertébrale, CHU Pellegrin, Bordeaux, Aquitaine, France

OBJECTIVE The objective of this study was to identify the risk factors of anterior bone loss (ABL) in cervical disc arthroplasty (CDA) and the subsequent effect of this phenomenon.

METHODS The authors performed a retrospective radiological review of 185 patients with a minimum 5-year follow-up after CDA (using Bryan, Discocerv, Mobi-C, or Baguera C). Postoperative radiographs were examined and compared to the initial postoperative films to determine the percentage of $A B L$. The relationship of $A B L$ to potential risk factors was analyzed.

RESULTS Complete radiological assessment was available in 145 patients with 193 CDRs and 383 endplates (average age 45 years, range $25-65$ years, $54 \%$ women). ABL was identified in $63.7 \%$ of CDRs $(48.7 \%$ mild, $11.9 \%$ moderate, $3.1 \%$ severe $)$. Age $(p=0.770)$, sex $(p=0.200)$, postoperative alignment $(p=0.330)$, midflexion point $(p=0.509)$, maximal flexion $(p=0.080)$, and extension $(p=0.717)$ did not relate to $A B L$. There was no significant difference in the rate of severe ABL between implants. Multilevel surgery conferred an increased risk of any and severe $A B L(p=0.013$ for both). The upper endplate, defined as superior to the CDA, was more commonly involved $(p=0.008)$, but there was no significant difference whether the endplate was between or not between implants $(p=0.226)$. The development of $A B L$ did not affect the long-term range of movement (ROM) of the CDA, but did increase the overall risk of autofusion. ABL was not associated with pain or functional deficits. No patients required a reoperation or revision of their implant during the course of this study, and there were no cases of progressive $A B L$ beyond the first year.

CONCLUSIONS ABL is common in all implant types assessed, although most is mild. Age, sex, postoperative alignment, ROM, and midflexion point do not relate to this phenomenon. However, the greater the number of levels operated, the higher the risk of developing $A B L$. The development of $A B L$ has no long-term effect on the mechanical functioning of the disc or necessity for revision surgery, although it may increase the rate of autofusion.

https://thejns.org/doi/abs/10.3171/2018.1.SPINE171018

KEYWORDS cervical disc replacement; disc arthroplasty; bone loss; osteolysis; avascular necrosis; stress shielding

$\mathrm{C}$ ERVICAL disc arthroplasty (CDA) has been growing in popularity since its first use in $1964 .{ }^{21}$ This has been supported by its clinical success and theoretical preservation of adjacent levels. ${ }^{3,5,12,17,20,23,27}$ However, this procedure is not without complications and the longterm survival of the implant remains to be seen. ${ }^{7,22}$

One potential complication that has gained recent interest is anterior bone loss (ABL) ${ }^{13,14,24,26}$ This phenomenon has been reported in more than $50 \%$ of cases, although most cases appear to be mild with no midterm (5-year) detrimental effects. ${ }^{13}$ However, some ABL may expose the anterior portion of the implant and result in increased pain and disability within the first year. In addition, subchondral collapse and implant subsidence may result.

To date, the exact cause of this phenomenon remains unknown. Clearly, infection, debris deposition, micromo-

ABBREVIATIONS $A B L=$ anterior bone loss; $A C D F=$ anterior cervical discectomy and fusion; $A L L=$ anterior longitudinal ligament; $A P=$ anteroposterior; $C D A=$ cervical disc arthroplasty; $\mathrm{HO}=$ heterotrophic ossification; $\mathrm{NDI}=$ neck disability index; $\mathrm{ROM}=$ range of movement; VAS = visual analog scale.

SUBMITTED September 27, 2017. ACCEPTED January 24, 2018.

INCLUDE WHEN CITING Published online May 25, 2018; DOI: 10.3171/2018.1.SPINE171018. 



15,16,18,19,25 However, most ABL occurs within the first 3 months and is nonprogressive. ${ }^{13}$ This is not consistent with infection, debris deposition, or micromotion, and therefore an alternative cause is likely.

Controversy remains as to whether the surgical approach or the implant is the cause of $\mathrm{ABL}$, especially considering the lack of recognition of this phenomenon in anterior cervical discectomy and fusion (ACDF). This study therefore aimed to examine the risk factors associated with ABL in CDA, specifically patient age and sex, as well as the potentially modifiable risk factors of implant type, alignment, number of levels operated, and motion. In addition, we aimed to determine the clinical affect of this phenomenon.

\section{Methods \\ Study Population and Data Collection}

A retrospective review was performed of 185 patients with prospectively collected standardized anteroposterior (AP), lateral, and flexion/extension radiographs of CDAs performed within our institution with a minimum 5-year follow-up. The implants included the Bryan disc from Medtronic (46 patients), Discocerv from Alphatech Spine (41 patients), Mobi-C from LDR (39 patients), and Baguera C from Spineart (59 patients).

$\mathrm{ABL}$ was recorded as a percentage of AP subchondral vertebral body length, referenced from the posterior vertebral body line, at follow-up compared with the immediate postoperative lateral radiograph. One of the authors (D.C.K.) determined the degree of ABL and resolved any controversies with another author (D.T.C.).

Implant uncovering was defined as more than $2 \mathrm{~mm}$ of anterior implant exposure; endplate collapse or implant subsidence was defined as a kyphotic change of more than $5^{\circ}$ in the implant position relative to the posterior vertebral line or more than $2 \mathrm{~mm}$ of height loss of the implant relative to the anterior or posterior vertebral body height on the immediate postoperative radiograph.

Each endplate was analyzed in isolation, such that each implant had 2 endplates assessed (upper and lower being superior and inferior to the CDA, respectively). An endplate was defined as being between implants if its adjacent disc was operated on (using either CDA or ACDF). In contrast, it was defined as "not between" implants if its adjacent disc was not operated on (i.e., the upper endplate of the most cephalad implant or the lower endplate of the most caudal implant as no "skipped level" procedures were included).

Endplates that were not clearly visible on the radiographs were excluded. Comparative radiographs were studied at 3 months, 6 months, 1 year, and yearly after that, with a minimum follow-up of 5 years. For each time interval, $\mathrm{ABL}$ was assessed. If the patient failed to have a radiograph at the intended time interval, the $\mathrm{ABL}$ for that time interval was not recorded, unless there was no difference between the previous and subsequent radiographs, in which case the ABL was recorded as the same amount as the adjacent time periods.

ABL was grouped into 3 groups: mild (bone loss of
$5 \%$ or less), moderate (bone loss of $6 \%-10 \%$ ), and severe (bone loss $>10 \%$ ). ABL was recorded as the maximum ABL identified throughout the duration of the study.

The immediate postoperative standing lateral radiograph was used to determine sagittal alignment of the operative level based on the posterior vertebral cortex as described by Harrison and colleagues. ${ }^{11}$ In addition, the initial flexion/extension views were analyzed to determine the initial range of movement (ROM) and the midflexion point, defined as the midpoint between maximal flexion and maximal extension. These measurements were based on the relative angles between the upper and lower components of each implant, with extension defined as posterior convergence or posterior disc closing, and flexion defined as anterior convergence or anterior disc closing.

The ROM was reassessed on the most recent radiographs and compared to the initial films. Heterotrophic ossification (HO) and autofusion rates were also analyzed on the most recent radiographs. Visual analog scale (VAS) scores for neck and arm pain were recorded preoperatively, 3 months postoperatively, and at 5 years postoperatively. The neck disability index (NDI) was recorded at 5 years postoperatively. These scores were correlated with the maximal ABL identified in each patient. The clinical notes were reviewed for reoperation or revision procedures.

\section{Statistical Analysis}

A series of descriptive statistics was recorded initially to describe this sample of respondents. Differences in proportions tests were conducted to determine whether the percentage of ABL significantly differed on the basis of type, with Spearman's correlations conducted to determine the association between the continuous measure of ABL and postoperative alignment, ROM, flexion, extension, and the midflexion point. Differences in proportions z-tests were also conducted to determine whether a significant difference in each category of ABL was present on the basis of each endplate. Following this, chi-square analyses were conducted to determine the association between various categories of maximal endplate ABL and age, sex, the number of levels operated, between versus not between implants, $\mathrm{HO}$, fusion, and combined $\mathrm{HO}$ and fusion. A series of ANOVAs sought to determine whether the majority of this study's outcome measures significantly differed on the basis of degree of ABL. ANOVA was also conducted to determine whether ABL significantly differed on the basis of number of operated levels, with a t-test conducted to determine whether postoperative alignment significantly differed on the basis of severe ABL.

VAS and NDI results were compared between ABL groups using a 1-way ANOVA. Where these analyses indicated significant associations, pairwise comparisons among the ABL groups were undertaken. Statistical analysis was performed using SPSS software (IBM Corp.). Statistical significance was defined as a $\mathrm{p}$ value of less than 0.05 .

\section{Results}

Of the 185 patients analyzed, complete radiological assessment was available in 145 patients and 193 CDAs. The 
TABLE 1. Degree of ABL identified per CDA

\begin{tabular}{|c|c|c|c|c|c|}
\hline \multirow[b]{2}{*}{ Implant Type } & \multicolumn{4}{|c|}{ Degree of $A B L$} & \multirow[b]{2}{*}{ Total } \\
\hline & None & Mild & Moderate & Severe & \\
\hline All & $70(36.3 \%)$ & $94(48.7 \%)$ & $23(11.9 \%)$ & $6(3.1 \%)$ & 193 \\
\hline Bryan & $24(42.9 \%)$ & $25(44.6 \%)$ & $7(12.5 \%)$ & $0(0 \%)$ & $56(29 \%)$ \\
\hline Discocerv & $23(52.3 \%)$ & $12(27.3 \%)$ & $4(9.1 \%)$ & $5(11.4 \%)$ & $44(23 \%)$ \\
\hline Mobi-C & $3(8.1 \%)$ & $23(62.2 \%)$ & $10(27.05)$ & $1(2.7 \%)$ & $37(19 \%)$ \\
\hline Baguera C & $20(35.7 \%)$ & $34(60.7 \%)$ & $2(3.6 \%)$ & $0(0)$ & $56(29 \%)$ \\
\hline
\end{tabular}

average patient age was 45 years (range $25-65$ years), 54\% were women, and the most common level operated was C5-6 (range C3-4 to C6-7). One hundred three patients had a single-, 36 had a double-, and 6 had a triple-level CDA. Thirteen patients had a hybrid procedure with a concomitant ACDF at the time of CDA. The mean followup duration was 6.2 years (range $5-10$ years).

The implants analyzed included 56 Bryan CDAs (32 patients), 44 Discocerv CDAs (38 patients), 37 Mobi-C CDAs (31 patients), and 56 Baguera C CDAs (44 patients; Table 1). From these 193 CDAs, 383 endplates were assessed, including 55 upper and 56 lower Bryan, 44 upper and 44 lower Discocerv, 37 upper and 37 lower Mobi-C, and 54 upper and 56 lower Baguera C CDAs.

ABL was identified in $63.7 \%$ of CDAs and $55.4 \%$ of endplates (Tables 1 and 2). The maximal percentage of ABL always occurred within the first year. There were no cases of progressive ABL beyond this time. There was no significant difference in the overall rate of $\mathrm{ABL}$, or the rate of severe $\mathrm{ABL}$, found in relation to patient age or sex ( $\mathrm{p}=0.77$ and 0.20 , respectively).

Most ABL was mild, with $48.7 \%$ of CDAs $(44.6 \%$ of endplates) experiencing this phenomenon. Moderate ABL was identified in $11.9 \%$ of CDAs (8.9\% of endplates). Severe $\mathrm{ABL}$ was rare and occurred in $3.1 \%$ of CDAs $(1.8 \%$ of endplates). Endplate collapse was only observed when ABL affected $50 \%$ or more of the affected endplates.

Severe ABL was identified in 1 single-, 1 double-, and 1 triple-level Discocerv CDA (11.4\% of Discocerv CDAs) and 1 double-level Mobi-C CDA (2.7\% of Mobi-C CDAs).

The Mobi-C was significantly more affected by any ABL (mild, moderate, or severe) than the other implants $(p=0.001)$, although the majority were mild. There were no other significant differences between implants.

Of the 383 endplates assessed, 55.4\% were affected by ABL (Table 2). The overall rate of any ABL between up- per and lower endplates was significantly different $(62.1 \%$ and $48.7 \%$, respectively; $\mathrm{p}=0.008$ ). However, the rate of severe $\mathrm{ABL}$ did not reach statistical significance $(\mathrm{p}=$ $0.718)$.

The number of CDAs performed related to the risk of any and severe ABL ( $\mathrm{p}=0.029$ and 0.002 , respectively; Table 3). This result was similar when including hybrid procedures, where there was a relationship between the number of levels operated and any as well as severe ABL $(\mathrm{p}=0.013$ and 0.013 , respectively; Table 4).

In multilevel surgery, including hybrid surgery, ABL was identified in $55.8 \%$ of endplates between implants and $63.8 \%$ of those not between implants. There was no significant difference in the rate of ABL between or not between implants $(\mathrm{p}=0.226$; Table 5$)$.

There was no significant relationship between the initial postoperative alignment, flexion, extension, or ROM and the development of any ABL (Table 6). Nor was there a significant relationship between any of these variables and the development of severe ABL. Furthermore, there was no correlation identified between the maximum percentage of ABL and these variables (Table 6). However, there was a significant relationship between the development of ABL and the rate of autofusion ( $p=0.050)$. There was no such relationship between ABL and the development of isolated HO ( $\mathrm{p}=0.132)$, but combined $\mathrm{HO}$ and fusion was significantly increased $(p=0.002)$ in the presence of ABL (Table 7).

The was no significant difference in VAS or NDI scores except that the preoperative VAS arm score was lower in those who did not develop any ABL than in those who did (Table 8). None of the initial 185 patients underwent a reoperation or revision procedure during the timeframe of this study, and therefore those excluded for a lack of complete radiographic follow-up were excluded because they had undergone another procedure.

TABLE 2. Degree of ABL per endplate

\begin{tabular}{|c|c|c|c|c|c|}
\hline \multirow[b]{2}{*}{ Endplate } & \multicolumn{4}{|c|}{ Degree of $A B L$} & \multirow[b]{2}{*}{ Total } \\
\hline & None & Mild & Moderate & Severe & \\
\hline Upper & 72 (37.9\%) & $96(50.5 \%)$ & $19(10.0 \%)$ & $3(1.6 \%)$ & $190(49.6 \%)$ \\
\hline Lower & $99(51.3 \%)$ & $75(38.9 \%)$ & $15(7.8 \%)$ & $4(2.1 \%)$ & $193(50.4 \%)$ \\
\hline Total & $171(44.6 \%)$ & $171(44.6 \%)$ & $34(8.9 \%)$ & $7(1.8 \%)$ & 383 \\
\hline$p$ value & $0.008^{*}$ & $0.022^{*}$ & 0.443 & 0.718 & \\
\hline
\end{tabular}

\footnotetext{
* Statistically significant results between upper and lower endplates.
} 
TABLE 3. Degree of ABL in each CDA related to the number of CDA levels

\begin{tabular}{lcccc}
\hline \multirow{2}{*}{ ABL } & \multicolumn{3}{c}{ CDA Level } & \\
\cline { 2 - 4 } None & Single & Double & Triple & Total \\
\hline Mild & $44(42.7 \%)$ & $24(33.3 \%)$ & $2(11.1 \%)$ & $70(36.3 \%)$ \\
\hline Moderate & $46(44.7 \%)$ & $40(55.6 \%)$ & $8(44.4 \%)$ & $94(48.7 \%)$ \\
\hline Severe & $12(11.7 \%)$ & $6(8.3 \%)$ & $5(27.8 \%)$ & $23(11.9 \%)$ \\
\hline Total & $103(53.4 \%)$ & $72(37.3 \%)$ & $18(9.3 \%)$ & 193 \\
\hline
\end{tabular}

TABLE 4. Maximal degree of ABL in each CDA related to the number of levels operated, including hybrid procedures

\begin{tabular}{lccrc}
\hline \multirow{2}{*}{ ABL } & \multicolumn{3}{c}{ No. of Levels Operated } & \multirow{2}{*}{ Total } \\
\cline { 2 - 4 } None & $39(45.3 \%)$ & $28(33.3 \%)$ & $3(13.0 \%)$ & $70(36.3 \%)$ \\
\hline Mild & $36(41.9 \%)$ & $47(56.0 \%)$ & $11(47.8 \%)$ & $94(48.7 \%)$ \\
\hline Moderate & $10(11.6 \%)$ & $7(8.3 \%)$ & $6(26.1 \%)$ & $23(11.9 \%)$ \\
\hline Severe & $1(1.2 \%)$ & $2(2.4 \%)$ & $3(13.0 \%)$ & $6(3.1 \%)$ \\
\hline Total & $86(44.6 \%)$ & $84(43.5 \%)$ & $23(11.9 \%)$ & 193 \\
\hline
\end{tabular}

\section{Discussion}

Consistent with the previous literature, $\mathrm{ABL}$ in this series was common $(63.7 \%$ of CDAs), occurred within the first year, and did not progress after this point. ${ }^{13}$ Most ABL was mild (ABL of $5 \%$ or less in $48.7 \%$ of CDAs), with only $3.1 \%$ of CDAs affected by severe ABL (ABL $>10 \%$ ). Anterior exposure of the implant was noted in moderate and severe ABL, but subchondral collapse and implant subsidence was only seen in severe ABL and only when more than $50 \%$ of the subchondral bone was resorbed.

We found no relationship between a patient's age or sex and their risk of developing ABL. All 4 implant types in this study were affected by ABL. Within the published literature, where this phenomenon has been specifically analyzed, all implants are affected by ABL. . $^{13,14,24,26}$ Our series found that the Mobi-C implant had an apparently higher rate of ABL. We are uncertain why this implant experienced a higher rate of ABL, but it may be related to the implant design or surgical exposure. In either case, most ABL was mild and likely clinically insignificant. It also had a lower rate of severe ABL than the Discocerv CDA, which had the highest rate of severe ABL (11.4\%), but this was related to only 3 patients and did not reach statistical significance. Therefore, this study cannot delineate whether a specific prosthesis has an increased predisposition for developing clinically significant $\mathrm{ABL}$ and we would advocate further research in this area.

This study found that the upper endplate was at greater risk of developing ABL than the lower endplate (62.1\% and $48.7 \%$, respectively; $p=0.008$ ). However, most ABL was mild or moderate and no significant difference between the endplate affected in severe cases was found. This finding supports the theory that ABL develops because of a lack of traction from the resected anterior longitudinal ligament (ALL). Because the ALL attaches to the beak or tubercle of the inferior portion of the anterior surface of a cervical vertebra, and this region is otherwise nonloaded, this region resorbs when the traction is removed. In contrast, the upper anterior portion of a vertebra does not have a reciprocal tubercle and all bone remains axially loaded and its resorption is likely to be less affected by ALL resection.

The result also supports the theory of a direct osteolytic insult. Due to the flat surface of a superior endplate, surgeons rarely need extensive exposure of the anterior rim of the inferior vertebra. In contrast, the dome shape of an inferior endplate and the overhanging anterior "beak" can obscure the visualization of the intervertebral disc. Therefore, there may be a preference to more extensively clear this zone of soft tissue for improved visualization, thus causing a greater insult to this region than the reciprocal region of the inferior vertebra.

This study also found that the more levels operated on per patient, the more likely each $\mathrm{CDA}$ is to experience $\mathrm{ABL}$. For a single-level procedure the risk of any $\mathrm{ABL}$ was $54.7 \%$, for a double level the risk per CDA was $66.7 \%$, and for a triple level the risk was $87.0 \%(p=0.013)$. The risk of the radiographically concerning $(>10 \%)$ ABL was also significantly increased in multilevel surgery $(1.2 \%$ in single-level, $2.4 \%$ in double-level, and $13.0 \%$ in triplelevel surgery; $\mathrm{p}=0.013$ ).

This finding is consistent with the basic orthopedic principle that the more extensive the dissection and softtissue stripping, the greater the bone insult. However, we could not find a significant difference in the rate of ABL between or not between implants $(p=0.226)$, suggesting that the local dissection of each endplate does not change in multilevel surgery or there is another cause for this phenomenon.

TABLE 5. Degree of ABL noted in multilevel CDAs related to the endplates either between the implants or not between the implants

\begin{tabular}{|c|c|c|c|c|c|}
\hline \multirow[b]{2}{*}{ Endplate Position } & \multicolumn{4}{|c|}{ Degree of $A B L$} & \multirow[b]{2}{*}{ Total } \\
\hline & None & Mild & Moderate & Severe & \\
\hline Between implants & $50(56.8 \%)$ & $49(45.8 \%)$ & $10(58.8 \%)$ & $4(66.7 \%)$ & $113(51.8 \%)$ \\
\hline Not between implants & $38(43.2 \%)$ & $58(54.2 \%)$ & $7(41.2 \%)$ & $2(33.3 \%)$ & $105(48.2 \%)$ \\
\hline$p$ value & 0.226 & 0.08 & 0.548 & 0.461 & \\
\hline
\end{tabular}


TABLE 6. Postoperative parameters dependent on the degree of $A B L$

\begin{tabular}{|c|c|c|c|c|c|c|}
\hline \multirow[b]{2}{*}{ Postop Parameter } & \multicolumn{4}{|c|}{ Degree of $A B L$} & \multirow[b]{2}{*}{ p Value } & \multirow{2}{*}{$\begin{array}{l}\text { Spearman's } \\
\text { Correlation }\end{array}$} \\
\hline & None & Mild & Moderate & Severe & & \\
\hline Immediate postop alignment & $0.2^{\circ}$ & $-1.5^{\circ}$ & $-1.1^{\circ}$ & $1.3^{\circ}$ & 0.330 & 0.072 \\
\hline Initial flexion & $3.1^{\circ}$ & $2.0^{\circ}$ & $5.3^{\circ}$ & $-0.2^{\circ}$ & 0.080 & -0.013 \\
\hline Initial extension & $3.3^{\circ}$ & $3.2^{\circ}$ & $4.3^{\circ}$ & $5.3^{\circ}$ & 0.717 & 0.013 \\
\hline Initial ROM & $6.4^{\circ}$ & $5.1^{\circ}$ & $9.6^{\circ}$ & $5.2^{\circ}$ & 0.434 & -0.013 \\
\hline Initial midflexion point & $-0.1^{\circ}$ & $-0.8^{\circ}$ & $0.2^{\circ}$ & $-2.8^{\circ}$ & 0.509 & -0.047 \\
\hline Late flexion & $3.8^{\circ}$ & $3.6^{\circ}$ & $5.7^{\circ}$ & $-0.3^{\circ}$ & 0.156 & -0.060 \\
\hline Late extension & $2.4^{\circ}$ & $4.1^{\circ}$ & $5.5^{\circ}$ & $5.0^{\circ}$ & 0.091 & -0.046 \\
\hline Late ROM & $6.2^{\circ}$ & $7.6^{\circ}$ & $11.2^{\circ}$ & $4.3^{\circ}$ & 0.581 & 0.023 \\
\hline
\end{tabular}

For alignment, a negative value depicts lordosis.

To further delineate other potential causes, we assessed postoperative radiographic parameters but found no relationship between ABL and the local alignment, ROM, maximal flexion, maximal extension, or the midflexion point of a CDA. One previous suggestion was that the cause of $\mathrm{ABL}$ might be anterior vertebral hyperpressure from the implant. While this study does not present vertebral pressure recordings, the fact that the local alignment did not vary between those affected and those unaffected by $\mathrm{ABL}$ suggests that the implants causing $\mathrm{ABL}$ were not oversized. Furthermore, the midflexion point was not more anterior, nor was the flexion greater in CDAs affected by ABL, thus reducing the likelihood of anterior hyperpressure being the cause of ABL. The results, therefore, support the theory that ABL is a result of the surgical approach rather than the implant, and that implant position, alignment, function, or mechanics do not relate to this phenomenon.

As evidenced by equivalent ROM between those CDAs unaffected and those affected by ABL, including severe $\mathrm{ABL}, \mathrm{ABL}$ does not affect the long-term mechanical functioning of the implants in this series. However, ABL was significantly associated with the subsequent autofusion $(\mathrm{p}=0.050)$ of the implant and may therefore predispose to this complication. Considering our proposal that the likely cause of ABL is surgical exposure, rather than implant specific, extrapolating our results makes for an interesting discussion as to whether the rates of autofusion can be reduced with surgical technique.

Although it seems biologically implausible that an equivalent final follow-up ROM was found despite a higher rate of autofusion in those with ABL, we believe

TABLE 7. Percentage of CDAs with $\mathrm{HO}$ and/or autofusion dependent on the degree of $A B L$

\begin{tabular}{lrrrrr}
\hline \multirow{2}{*}{ Variable } & \multicolumn{4}{c}{ Degree of ABL } & \\
\cline { 2 - 5 } & None & \multicolumn{1}{c}{ Mild } & Moderate & Severe & Total \\
\hline HO & $20.0 \%$ & $9.6 \%$ & $4.3 \%$ & $16.7 \%$ & $13.0 \%$ \\
\hline Autofusion & $21.4 \%$ & $9.6 \%$ & $4.3 \%$ & $0.0 \%$ & $13.0 \%$ \\
\hline HO and autofusion & $41.4 \%$ & $19.1 \%$ & $8.7 \%$ & $16.7 \%$ & $25.9 \%$ \\
\hline
\end{tabular}

that this results from the small difference of ROM identified between those with (mean $6.2^{\circ}$ ) and without (mean $\left.8.1^{\circ}\right) \mathrm{ABL}$ not reaching statistical or clinical significance (Table 6).

We found no significant relationship between the degree of ABL and patient pain (VAS neck and arm scores) at 3 months. This contrasts with the results of Heo and colleagues, who found significantly worse pain in those with anterior exposure of their implant during the first year in their study of 48 patients with a Baguera $\mathrm{C}$ implant. ${ }^{13}$ However, our study of 145 patients with multiple implants utilizes a different grading system and assessed patients at 3 months postoperatively. It is therefore possible that our study failed to identify the peak period of pain during the first year, despite ABL typically commencing within the first 3 months, or that our greater number of patients reduces the intrinsic variations observed with smaller sample sizes. Similarly, we included multiple different nonkeeled implants to ensure that the radiographic and clinical outcomes were not implant specific.

Our results show that ABL causes no significant difference in pain or functional outcomes at 5 years. This is consistent with the results of Heo and colleagues. ${ }^{13}$ Furthermore, no patient required a revision or reoperation during the timeframe of this study, suggesting that clinicians can safely monitor ABL without the need for revision, even with severe ABL. However, the longer-term affect on the adjacent levels, particularly with implant subsidence and the development of a local kyphotic deformity, remains unknown.

This study lacks a correlation with the patient's medical comorbidities and activity levels, which may affect ABL. Similarly, the intraoperative degree of surgical insult to the anterior vertebra is not known. Lastly, because of the limited numbers of each implant type and the rareness of severe ABL, an accurate determination of each prosthetic design's risk is limited. Further research should aim to account for these shortcomings.

\section{Conclusions}

This study confirms that ABL is common in all implant types assessed and demonstrates that age and sex do not confer a risk. Both endplates can be affected but 
TABLE 8. Comparative pain and functional outcome scores according to the degree of $A B L$

\begin{tabular}{|c|c|c|c|c|c|c|c|}
\hline \multirow{2}{*}{$\begin{array}{l}\text { Degree } \\
\text { of } A B L\end{array}$} & \multicolumn{3}{|c|}{ VAS Neck Score } & \multicolumn{3}{|c|}{ VAS Arm Score } & \multirow{2}{*}{$\begin{array}{c}\text { NDI } 5 \text { Yrs } \\
\text { Postop }\end{array}$} \\
\hline & Preop & 3 Mos Postop & 5 Yrs Postop & Preop & 3 Mos Postop & 5 Yrs Postop & \\
\hline None & 5.8 & 2.6 & 2.3 & 6.2 & 1.7 & 1.5 & 18.9 \\
\hline Mild & 6.1 & 1.5 & 1.3 & 7.4 & 1.3 & 0.7 & 11.2 \\
\hline Moderate & 6.6 & 2.5 & 1.8 & 7.6 & 1.5 & 1.0 & 10.1 \\
\hline Severe & 5.9 & 3.3 & 2.7 & 8.5 & 1.4 & 2.8 & 9.0 \\
\hline$p$ value & 0.737 & $0.023^{*}$ & 0.131 & 0.897 & 0.291 & 0.129 & 0.094 \\
\hline
\end{tabular}

* Denotes statistical significance.

the upper endplate is at greater risk. The more levels operated, the more likely a CDA is to develop ABL, including severe ABL, but this does not specifically affect the endplates between implants. Postoperative alignment, range of movement, and midflexion point do not relate to this phenomenon, and the development of ABL has no longterm effect on the mechanical functioning of the CDA or need for revision surgery, although it may increase the rate of autofusion.

\section{Acknowledgments}

We thank Dr. David Kremelberg and Prof. Chris Frampton for their statistical analysis of the data, and Glynny Kieser for her editorial input.

\section{References}

1. Au AG, James Raso V, Liggins AB, Amirfazli A: Contribution of loading conditions and material properties to stress shielding near the tibial component of total knee replacements. J Biomech 40:1410-1416, 2007

2. Boyle C, Kim IY: Comparison of different hip prosthesis shapes considering micro-level bone remodeling and stressshielding criteria using three-dimensional design space topology optimization. J Biomech 44:1722-1728, 2011

3. Burkus JK, Traynelis VC, Haid RW Jr, Mummaneni PV: Clinical and radiographic analysis of an artificial cervical disc: 7-year follow-up from the Prestige prospective randomized controlled clinical trial. Clinical article. J Neurosurg Spine 21:516-528, 2014

4. Chen CM, Tsai WC, Lin SC, Tseng CS: Effects of stemmed and nonstemmed hip replacement on stress distribution of proximal femur and implant. BMC Musculoskelet Disord 15:312, 2014

5. Coric D, Kim PK, Clemente JD, Boltes MO, Nussbaum M, James S: Prospective randomized study of cervical arthroplasty and anterior cervical discectomy and fusion with long-term follow-up: results in 74 patients from a single site. J Neurosurg Spine 18:36-42, 2013

6. Demetracopoulos CA, Halloran JP, Maloof P, Adams SB Jr, Parekh SG: Total ankle arthroplasty in end-stage ankle arthritis. Curr Rev Musculoskelet Med 6:279-284, 2013

7. Denaro V, Papalia R, Denaro L, Di Martino A, Maffulli N: Cervical spinal disc replacement. J Bone Joint Surg Br 91:713-719, 2009

8. Elhassan B, Ozbaydar M, Higgins LD, Warner JJ: Glenoid reconstruction in revision shoulder arthroplasty. Clin Orthop Relat Res 466:599-607, 2008

9. Fraser JF, Werner S, Jacofsky DJ: Wear and loosening in total knee arthroplasty: a quick review. J Knee Surg 28:139-144, 2015

10. Gallo J, Goodman SB, Konttinen YT, Wimmer MA, Holinka
M: Osteolysis around total knee arthroplasty: a review of pathogenetic mechanisms. Acta Biomater 9:8046-8058, 2013

11. Harrison DE, Harrison DD, Cailliet R, Troyanovich SJ, Janik TJ, Holland B: Cobb method or Harrison posterior tangent method: which to choose for lateral cervical radiographic analysis. Spine (Phila Pa 1976) 25:2072-2078, 2000

12. Heller JG, Sasso RC, Papadopoulos SM, Anderson PA, Fessler RG, Hacker RJ, et al: Comparison of BRYAN cervical disc arthroplasty with anterior cervical decompression and fusion: clinical and radiographic results of a randomized, controlled, clinical trial. Spine (Phila Pa 1976) 34:101-107, 2009

13. Heo DH, Lee DC, Oh JY, Park CK: Bone loss of vertebral bodies at the operative segment after cervical arthroplasty: a potential complication? Neurosurg Focus 42(2):E7, 2017

14. Kim SH, Chung YS, Ropper AE, Min KH, Ahn TK, Won KS, et al: Bone loss of the superior adjacent vertebral body immediately posterior to the anterior flange of Bryan cervical disc. Eur Spine J 24:2872-2879, 2015

15. Klimkiewicz JJ, Iannotti JP, Rubash HE, Shanbhag AS: Aseptic loosening of the humeral component in total shoulder arthroplasty. J Shoulder Elbow Surg 7:422-426, 1998

16. Morrey BF, Bryan RS: Complications of total elbow arthroplasty. Clin Orthop Relat Res 170:204-212, 1982

17. Mummaneni PV, Amin BY, Wu JC, Brodt ED, Dettori JR, Sasso RC: Cervical artificial disc replacement versus fusion in the cervical spine: a systematic review comparing longterm follow-up results from two FDA trials. J Evid Based Spine Care 3 (Suppl 1):S59-S66, 2012

18. Orishimo KF, Claus AM, Sychterz CJ, Engh CA: Relationship between polyethylene wear and osteolysis in hips with a second-generation porous-coated cementless cup after seven years of follow-up. J Bone Joint Surg Am 85-A:1095-1099, 2003

19. Panegrossi G, Ceretti M, Papalia M, Casella F, Favetti F, Falez F: Bone loss management in total knee revision surgery. Int Orthop 38:419-427, 2014

20. Radcliff K, Coric D, Albert T: Five-year clinical results of cervical total disc replacement compared with anterior discectomy and fusion for treatment of 2-level symptomatic degenerative disc disease: a prospective, randomized, controlled, multicenter investigational device exemption clinical trial. J Neurosurg Spine 25:213-224, 2016

21. Reitz H, Joubert MJ: Intractable headache and cervicobrachialgia treated by complete replacement of cervical intervertebral discs with a metal prosthesis. S Afr Med J 38:881-884, 1964

22. Skovrlj B, Lee DH, Caridi JM, Cho SKW: Reoperations following cervical disc replacement. Asian Spine J 9:471-482, 2015

23. Traynelis VC, Arnold PM, Fourney DR, Bransford RJ, Fischer DJ, Skelly AC: Alternative procedures for the treatment of cervical spondylotic myelopathy: arthroplasty, oblique 
corpectomy, skip laminectomy: evaluation of comparative effectiveness and safety. Spine (Phila Pa 1976) 38 (22 Suppl 1):S210-S231, 2013

24. Tumialán LM, Gluf WM: Progressive vertebral body osteolysis after cervical disc arthroplasty. Spine (Phila Pa 1976) 36:E973-E978, 2011

25. Vasso M, Beaufils P, Cerciello S, Schiavone Panni A: Bone loss following knee arthroplasty: potential treatment options. Arch Orthop Trauma Surg 134:543-553, 2014

26. Veruva SY, Lanman TH, Hanzlik JA, Kurtz SM, Steinbeck MJ: Rare complications of osteolysis and periprosthetic tissue reactions after hybrid and non-hybrid total disc replacement. Eur Spine J 24 (Suppl 4):S494-S501, 2015

27. Wu JC, Hsieh PC, Mummaneni PV, Wang MY: Spinal motion preservation surgery. BioMed Res Int 2015:372502, 2015

\section{Disclosures}

Dr. Boissière reports being a consultant to Spineart. Dr. Obeid reports being a consultant to DePuy Synthes and Medtronic; receiving royalties from Alphatec Spine, Clariance, and Spineart; and receiving clinical or research support for the study from DePuy Synthes. Dr. Pointillart reports being a consultant to Spineart and Biomet.

\section{Author Contributions}

Conception and design: Kieser. Acquisition of data: Kieser. Analysis and interpretation of data: Kieser, Cawley. Drafting the article: Kieser, Cawley, Fujishiro. Critically revising the article: all authors. Reviewed submitted version of manuscript: Kieser, Fujishiro, Mazas, Boissière, Obeid, Pointillart, Vital, Gille. Approved the final version of the manuscript on behalf of all authors: Kieser. Statistical analysis: Kieser. Administrative/technical/material support: Kieser, Gille. Study supervision: Kieser, Gille.

\section{Correspondence}

David Kieser: Canterbury District Health Board, Christchurch, New Zealand. kieserdavid@gmail.com. 